\title{
Ionic Mechanisms of Microsecond-Scale Spike Timing in Single Cells
}

\author{
Michael R. Markham ${ }^{1,2}$ and Harold H. Zakon ${ }^{2}$ \\ ${ }^{1}$ Department of Biology, The University of Oklahoma, Norman, Oklahoma 73019, and ${ }^{2}$ Section of Neurobiology and Institute for Neuroscience, The \\ University of Texas at Austin, Austin, Texas 78712
}

Electric fish image their environments and communicate by generating electric organ discharges through the simultaneous action potentials (APs) of electric organ cells (electrocytes) in the periphery. Steatogenys elegans generates a biphasic electrocyte discharge by the precisely regulated timing and waveform of APs generated from two excitable membranes present in each electrocyte. Current-clamp recordings of electrocyte APs reveal that the posterior membrane fires first, followed $30 \mu$ s later by an AP on the anterior membrane. This delay was maintained even as the onset of the first AP was advanced $>5 \mathrm{~ms}$ by increasing stimulus intensity and across multiple spikes during bursts of APs elicited by prolonged stimulation. Simultaneous cell-attached loose-patch recordings of $\mathrm{Na}^{+}$currents on each membrane revealed that activation voltage for $\mathrm{Na}^{+}$channels on the posterior membrane was $10 \mathrm{mV}$ hyperpolarized compared with $\mathrm{Na}^{+}$channels on the anterior membrane, with no differences in activation or inactivation kinetics. Computational simulations of electrocyte APs demonstrated that this difference in $\mathrm{Na}^{+}$current activation voltage was sufficient to maintain the proper firing order and the interspike delay. A similar difference in activation threshold has been reported for the $\mathrm{Na}^{+}$currents of the axon initial segment compared with somatic $\mathrm{Na}^{+}$channels of pyramidal neurons, suggesting convergent evolution of spike initiation and timing mechanisms across different systems of excitable cells.

Key words: action potential; electric organ; ion channels

\section{Introduction}

The location and timing of action potential (AP) initiation is critically important for transmitting information in neural systems (Bean, 2007). In central neurons, the axonal AP, which represents the integration of all neuronal inputs, is initiated in the distal axon initial segment (AIS) rather than the soma or proximal AIS (Palmer and Stuart, 2006; Meeks and Mennerick, 2007). At least two complementary mechanisms determine the site of AP initiation: a higher density of $\mathrm{Na}^{+}$channels in the AIS (Kole et al., 2008) and an $\sim 10 \mathrm{mV}$ hyperpolarizing shift in activation voltage of distal AIS $\mathrm{Na}^{+}$channels compared with somatic and proximal AIS channels (Colbert and Pan, 2002; Hu et al., 2009). These differences in $\mathrm{Na}^{+}$channel activation voltage arise because Nav1.6 channels are expressed in the soma and distal AIS, whereas Nav1.2 channels are localized to the proximal AIS (Hu et al., 2009). Where and when dendritic APs are generated is equally important for information processing (Johnston et al., 2003) and differences in $\mathrm{Na}^{+}$channel activation voltage is at least one mechanism responsible for determining the location and timing

\footnotetext{
Received Feb. 9, 2014; revised April 6, 2014; accepted April 8, 2014.

Author contributions: M.R.M. and H.H.Z. designed research; M.R.M. performed research; M.R.M. analyzed data; M.R.M. and H.H.Z. wrote the paper.

This work was supported by the National Science Foundation (Integrative Organismal Systems Grant 1257580 to M.R.M.) and the National Institutes of Health (Grant GM084879 to H.H.Z.).

The authors declare no competing financial interests.

Correspondence should be addressed to Michael R Markham, Department of Biology, The University of Oklahoma, 730 Van Vleet Oval, Norman, 0K 73019. E-mail: markham@ou.edu.

DOI:10.1523/JNEUROSCI.0615-14.2014

Copyright $\odot 2014$ the authors $\quad 0270-6474 / 14 / 346668-11 \$ 15.00 / 0$
}

of dendritic APs (Gasparini and Magee, 2002). Is the compartmentalization of $\mathrm{Na}^{+}$channels with different properties a general mechanism for regulating the location and timing of $\mathrm{AP}$ generation?

The location and timing of AP initiation is also essential for representing information in the electric sensory and communication systems of weakly electric fish. These fish generate electric organ discharges (EODs) in the surrounding water through synchronous APs of their peripheral electric organ cells (electrocytes) and sense distortions in the resulting electric fields to communicate and image their environment in darkness. The EOD waveform encodes information including species, sex, and individual identity (Hopkins and Bass, 1981; Friedman and Hopkins, 1998), as well as social status, reproductive status, and body condition (Gavassa et al., 2011; Gavassa et al., 2013). In the gymnotiform Steatogenys elegans, electrocytes generate biphasic discharges by coordinating two APs generated from two excitable membranes present in each electrocyte (Bennett and Grundfest, 1959; Bennett, 1971). The posterior membrane fires first, followed $\sim 30 \mu$ s later by an AP on the anterior membrane (Bennett, 1961). Changing these parameters modifies EOD amplitude and waveform (Markham and Stoddard, 2005), significantly altering the EOD's information content (Gavassa et al., 2011).

Here, we investigated AP initiation and the microsecond-scale timing of two independent APs generated by S. elegans electrocytes. We first quantified electrocyte AP properties and then characterized the ionic currents responsible for AP generation. We found an $\sim 10 \mathrm{mV}$ hyperpolarizing shift in the activation 
voltage of $\mathrm{Na}^{+}$channels on the posterior membrane. Computational simulations revealed that this mechanism is sufficient to initiate the posterior AP first and maintain the posterior-anterior AP delay within $3 \mu$ s despite large differences in stimulus intensity. These findings suggest that compartmentalization of $\mathrm{Na}^{+}$channels with different activation voltages is a convergent evolutionary solution for precisely regulating the location and timing of AP initiation across vastly different systems of excitable cells that represent and transmit information within or between organisms.

\section{Materials and Methods}

Animals. Fish were wild-caught male and female S. elegans (Sierra knife fish) from tropical South America obtained from Segrest Farms and ranging in size from 16 to $22 \mathrm{~cm}$. Fish were housed in groups of 4 or 8 in 20-1 or 40-1 tanks under a 12:12 light:dark cycle in a at $26 \pm 1^{\circ} \mathrm{C}$. Water conductivity was maintained at $400-600 \mu \mathrm{S} / \mathrm{cm}$. All methods were approved by the Institutional Animal Care and Use Committees of The University of Texas and The University of Oklahoma and complied with the guidelines given in the National Institutes of Health's Guide for the Care and Use of Laboratory Animals.

Solutions and reagents. The external saline for all electrophysiological recordings contained the following (in $\mathrm{mm}$ ): $114 \mathrm{NaCl}, 2 \mathrm{KCl}, 4$ $\mathrm{CaCl}_{2} \cdot 2 \mathrm{H}_{2} \mathrm{O}, 2 \mathrm{MgCl}_{2} \cdot 6 \mathrm{H}_{2} \mathrm{O}, 5$ HEPES, 6 glucose, $\mathrm{pH} 7.2$ with $\mathrm{NaOH}$ (all salts from Sigma-Aldrich). The $\mathrm{Na}^{+}$channel blocker tetrodotoxin (TTX) was purchased from Tocris Biosciences and the $\mathrm{K}^{+}$channel blockers Stichodactyla toxin and Tityustoxin from Alomone Laboratories. Toxins were dissolved in water at a stock concentration of $1 \mathrm{~mm}$, stored in single-use aliquots at $-20^{\circ} \mathrm{C}$, and then thawed and diluted in saline to working concentrations immediately before use.

Electrophysiology: general methods. Electric organs were harvested from S. elegans by cutting off a small $(1-2 \mathrm{~cm})$ piece of the narrow caudal tail filament, which consists only of soft tissue and is almost entirely composed of electric organ. This very brief procedure (the fish is out of the home tank for $<15 \mathrm{~s}$ ) is performed without anesthesia because induction and recovery from anesthesia causes more harm and stress for the fish than the tail clip itself. The skin was removed and the exposed electric organ pinned down in a Sylgard-coated recording chamber perfused (1 $\mathrm{ml} / \mathrm{min})$ with normal saline at room temperature $\left(23 \pm 1^{\circ} \mathrm{C}\right)$. The recording bath was grounded with a chlorided silver wire inserted into a $3 \mathrm{M} \mathrm{KCl}$ agar bridge.

Intracellular micropipettes were pulled from $1.2 \mathrm{~mm}$ thin-wall borosilicate glass and had resistances of $0.8-1.1 \mathrm{M} \Omega$ when filled with $3 \mathrm{M} \mathrm{KCl}$. Extracellular pipettes were made by breaking the tips of intracellular pipettes until they had resistances of $400-600 \mathrm{~K} \Omega$ when filled with normal saline. Loose-patch pipettes were fabricated by first pulling standard patch pipettes (1-2 $\mu \mathrm{m}$ tip diameter) from thick-walled borosilicate glass and then cutting and fire polishing the tips to diameters of $\sim 10-20 \mu \mathrm{m}$ (830 Microforge; Narishige). An Axoclamp 900A amplifier (Molecular Devices) was used for current-clamp and two-electrode voltage clamp (TEVC) using a unity-gain headstage (HS-9A x100; Molecular Devices) to record membrane potential and an X10 headstage (HS-9A x10; Molecular Devices) to deliver current. Extracellular recordings were made using a Dagan TEV200A amplifier in current-clamp mode. Two Axopatch 200B amplifiers (Molecular Devices) were used for loose-patch recordings. All amplifiers were controlled by a Digidata 1440 interface and PClamp 10.0 software (Molecular Devices). Data were digitized (100 $\mathrm{kHz}$, no filtering) and upsampled by cubic spline interpolation (MATLAB 'interp1' function; MathWorks) to enhance temporal resolution.

Electrophysiological data are reported as mean \pm SEM. Statistical comparisons and nonlinear curve fits were performed in MATLAB or GraphPad Prism software. Paired $t$ tests were used for comparisons of different parameters within cells. For repeated comparisons of the same parameters within cells, repeated-measures ANOVA was used. Significant omnibus ANOVAs were further analyzed by pairwise comparisons using Tukey's HSD to maintain experiment-wise $\alpha$ at 0.05 and in some cases by post hoc regression tests for linear trend.

Current-clamp electrophysiology. Electrocytes of S. elegans are large, disk-shaped cells $(\sim 200 \mu \mathrm{m}$ width $\times 250 \mu \mathrm{m}$ diameter $)$ innervated at
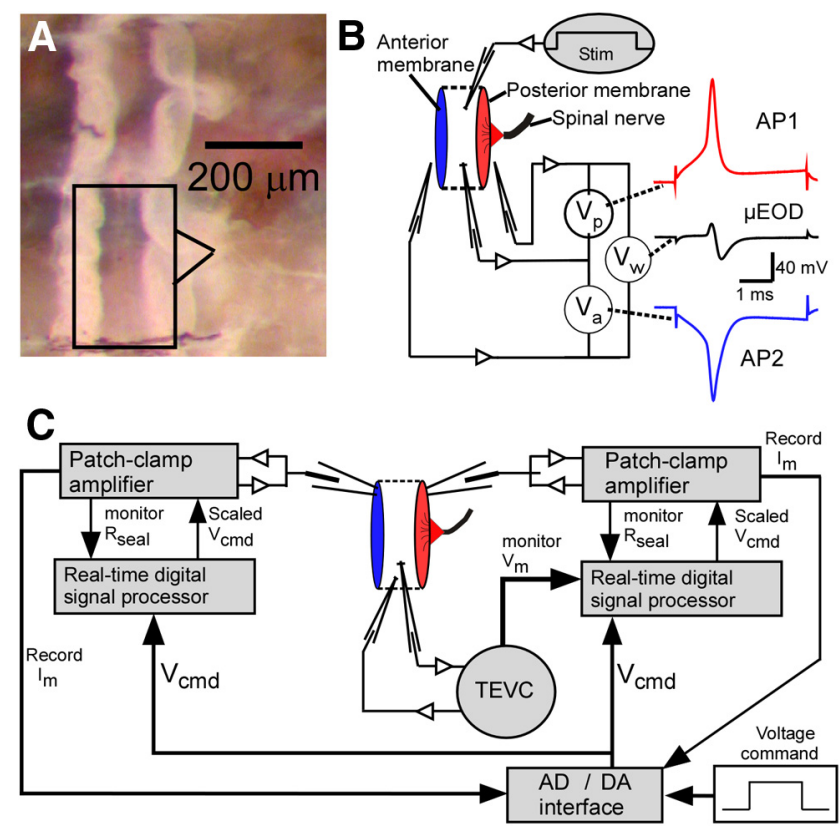

Figure 1. Electrocyte morphology and electrophysiological recording methods. A, Photograph of two $S$. elegans electrocytes in situ, posterior: right. Bottom electrocyte is outlined in black to highlight cell morphology. $\boldsymbol{B}$, Schematic of current-clamp recording methods. Two pipettes filled with $3 \mathrm{~m} \mathrm{KCl}$ penetrate the cell and two pipettes filled with bath saline are positioned just outside the anterior and posterior membranes. A depolarizing current step delivered via one intracellular pipette elicits the $\mu E 0 D$. The second intracellular pipette records the intracellular potential while the two extracellular micropipettes record extracellular potentials. Offline subtraction of the posterior extracellular record from the intracellular record yields the posterior-membrane voltage $\left(V_{\mathrm{p}}\right)$ and AP1, the posterior-face action potential. Subtraction of the anterior extracellular record from the intracellular record yields the anterior-membrane voltage $\left(V_{a}\right)$ and AP2, the anterior-face action potential (AP2 is shown as a negative-going spike because its depolarization phase produces tailward current). Subtraction of the posterior extracellular record from the anterior extracellular record yields the whole-cell voltage $\left(V_{\mathrm{w}}\right)$ and the $\mu E 0 D$. C, Schematic of loose-patch recording preparation (adapted from Markham, 2013; Fig. 2A). Two patch pipettes are positioned against the anterior and posterior active membrane. Two sharp pipettes penetrate the cell within $100 \mu \mathrm{m}$ of the patch pipettes and clamp the cell to the desired intracellular potential via TEVC ensuring that the voltage commands and currents in the patch pipette do not affect the membrane potential outside of the patches and maintaining a known intracellular potential that is necessary for scaling the patch pipette voltage commands to achieve the desired membrane potential across the patches. A real-time signal processor monitors seal resistance and membrane potential for each pipette before each trial and then scales the voltage-command waveforms in real-time to achieve the desired membrane potentials.

the apex of a stalk that projects from the posterior membrane (Fig. $1 A$ ). Both the posterior- and anterior-face membranes are excitable and the sequential APs of these two excitable membranes in series produce the electrocyte discharge ( $\mu \mathrm{EOD})$ that closely resembles the EOD measured in vivo (Bennett, 1961). The spinal nerve initiates the $\mu \mathrm{EOD}$, which is produced by sequential APs: the posterior face spikes first (AP1), followed $\sim 30 \mu$ s later by a spike from the noninnervated anterior face (AP2). These two APs sum to produce the biphasic $\mu$ EOD recorded differentially across the whole cell (Fig. $1 B$ ).

We recorded AP1, AP2, and the $\mu \mathrm{EOD}$ with multielectrode currentclamp procedures detailed previously (Fig. 1B; Bennett, 1961; Markham and Stoddard, 2005). A depolarizing current step was passed through one intracellular pipette to initiate the $\mu \mathrm{EOD}$. A second intracellular pipette recorded intracellular potential and two extracellular pipettes placed within $50 \mu \mathrm{m}$ of the anterior and posterior membranes recorded the extracellular anterior and posterior potentials. Subtraction of the posterior extracellular record from the intracellular record yields AP1, subtraction of the anterior extracellular record from the intracellular record yields AP2, and subtraction of the posterior extracellular record from the anterior extracellular record yields the $\mu \mathrm{EOD}$. Whole-cell passive prop- 
Table 1. Parameter values for the electrocyte model

\begin{tabular}{|c|c|c|}
\hline Parameter & $\begin{array}{l}\text { Anterior } \\
\text { compartment }\end{array}$ & $\begin{array}{l}\text { Posterior } \\
\text { compartment }\end{array}$ \\
\hline $\bar{g}_{N a}$ & $600 \mu S-1100 \mu S$ & $600 \mu S-1100 \mu S$ \\
\hline$V 50_{m}^{*}$ & $-54.20 \mathrm{mV}$ & $-64.12 \mathrm{mV}$ \\
\hline$k_{m}$ & 9.27 & 9.27 \\
\hline$V 50_{h}$ & $-100.82 \mathrm{mV}$ & $-100.82 \mathrm{mV}$ \\
\hline$k_{h}$ & -9.57 & -9.57 \\
\hline$\alpha_{m}$ & $0.2286 \mathrm{~ms}$ & $0.2286 \mathrm{~ms}$ \\
\hline$\mu_{m}$ & $-83.9 \mathrm{mV}$ & $-83.9 \mathrm{mV}$ \\
\hline$\sigma_{m}$ & $24.97 \mathrm{mV}$ & $24.97 \mathrm{mV}$ \\
\hline$\beta_{m}$ & $0.06128 \mathrm{~ms}$ & $0.06128 \mathrm{~ms}$ \\
\hline$\alpha_{h}^{*}$ & $1.653 \mathrm{~ms}$ & $0.753 \mathrm{~ms}$ \\
\hline$\mu_{h}$ & $-110.6 \mathrm{mV}$ & $-110.6 \mathrm{mV}$ \\
\hline$\sigma_{h}$ & $28.54 \mathrm{mV}$ & $28.54 \mathrm{mV}$ \\
\hline$\beta_{h}$ & $0.07900 \mathrm{~ms}$ & $0.07900 \mathrm{~ms}$ \\
\hline $\bar{g}_{A}$ & $400 \mu S-1500 \mu S$ & $400 \mu S-1500 \mu S$ \\
\hline$V 50_{a}$ & $-57.93 \mathrm{mV}$ & $-57.93 \mathrm{mV}$ \\
\hline$k_{a}$ & 20.97 & 20.97 \\
\hline$V 50_{b}$ & $-45.82 \mathrm{mV}$ & $-45.82 \mathrm{mV}$ \\
\hline$k_{b}$ & -17.26 & -17.26 \\
\hline$\alpha_{a}$ & $20.42 \mathrm{~ms}$ & $20.42 \mathrm{~ms}$ \\
\hline$\mu_{a}$ & $-71.98 \mathrm{mV}$ & $-71.98 \mathrm{mV}$ \\
\hline$\sigma_{a}$ & $12.42 \mathrm{mV}$ & $12.42 \mathrm{mV}$ \\
\hline$\beta_{a}$ & $0 \mathrm{~ms}$ & $0 \mathrm{~ms}$ \\
\hline$\alpha_{b}$ & $20.77 \mathrm{~ms}$ & $20.77 \mathrm{~ms}$ \\
\hline$\mu_{b}$ & $-75.99 \mathrm{mV}$ & $-75.99 \mathrm{mV}$ \\
\hline$\sigma_{b}$ & $46.49 \mathrm{mV}$ & $46.49 \mathrm{mV}$ \\
\hline$\beta_{b}$ & $9.11 \mathrm{~ms}$ & $9.11 \mathrm{~ms}$ \\
\hline $\bar{g}_{k}$ & $0-3000 \mu \mathrm{S}$ & $0-3000 \mu \mathrm{S}$ \\
\hline$V 50_{n}$ & $-28.64 \mathrm{mV}$ & $-28.64 \mathrm{mV}$ \\
\hline$k_{n}$ & 23.12 & 23.12 \\
\hline$\alpha_{n}$ & $25.13 \mathrm{~ms}$ & $25.13 \mathrm{~ms}$ \\
\hline$\mu_{n}$ & $-54.54 \mathrm{mV}$ & $-54.54 \mathrm{mV}$ \\
\hline$\sigma_{n}$ & $15.19 \mathrm{mV}$ & $15.19 \mathrm{mV}$ \\
\hline$\beta_{n}$ & $0.49 \mathrm{~ms}$ & $0.49 \mathrm{~ms}$ \\
\hline $\bar{g}_{L}$ & $5-9 \mu S$ & $5-9 \mu S$ \\
\hline $\bar{g}_{R}$ & $15-70 \mu \mathrm{S}$ & $15-70 \mu \mathrm{S}$ \\
\hline
\end{tabular}

*Parameters that differed between compartments.

erties were measured from membrane voltage responses to a $100 \mathrm{~ms}$ duration $100 \mathrm{nA}$ step pulse delivered $200 \mathrm{~ms}$ before the suprathreshold stimulation. AP amplitude was measured from the resting potential to the peak of the AP and AP duration was quantified as the AP width at half of this amplitude (AP half-width).

Two-electrode voltage clamp. Electroctyes have very long time constants, low resting resistances, and large membrane currents $(>10 \mu \mathrm{A})$. As a result, the rapidly activating $\mathrm{Na}^{+}$and delayed rectifier $\mathrm{K}^{+}$channels typically produced escape currents even at the maximum amplifier gain $(50,000 \mathrm{~V} / \mathrm{V})$. We did, however, use TEVC to analyze inward rectifier $\mathrm{K}^{+}$ currents present at steady state when the amplifier's DC gain is $10^{6} \mathrm{~V} / \mathrm{V}$. From a holding voltage of $-95 \mathrm{mV}$, voltage-clamp protocols consisted of $150 \mathrm{~ms}$ voltage steps in $10 \mathrm{mV}$ from $-140 \mathrm{mV}$ to $-80 \mathrm{mV}$, a membrane potential well below the activation voltage of the electrocytes' $\mathrm{Na}^{+}$channels and delayed rectifier $\mathrm{K}^{+}$channels.

Loose-patch clamp. We were unable to achieve gigaseal patch recordings on electroctyes, likely due to the presence of adherent connective tissue. We therefore used cell-attached loose-patch methods (Almers et al., 1983) to record the fast voltage-gated $\mathrm{Na}^{+}$and $\mathrm{K}^{+}$currents (Fig. 1C). The essential feature of the loose-patch technique is a low seal resistance $\left(R_{\mathrm{S}}\right)$, usually only a few $\mathrm{M} \Omega$. The pipette resistance $\left(R_{\mathrm{P}}\right)$ and $R_{\mathrm{S}}$ together form a non-negligible voltage divider, such that the command voltage applied to the pipette solution $\left(V_{\mathrm{P}}\right)$ produces an attenuated voltage at the pipette tip $\left(V_{\mathrm{T}}\right)$. By measuring $R_{\mathrm{P}}$ before approaching the cell and monitoring total resistance $\left(R_{\mathrm{P}}+R_{\mathrm{S}}\right)$ after contacting the cell, it is possible to calculate a correction factor $A=R_{\mathrm{S}} /\left(R_{\mathrm{P}}+R_{\mathrm{S}}\right)$ and then scale $V_{\mathrm{P}}$ by $1 / A$ to produce the desired $V_{\mathrm{T}}$. Recorded patch currents are then divided by $A$ to compensate for the leakage current through $R_{\mathrm{S}}$.
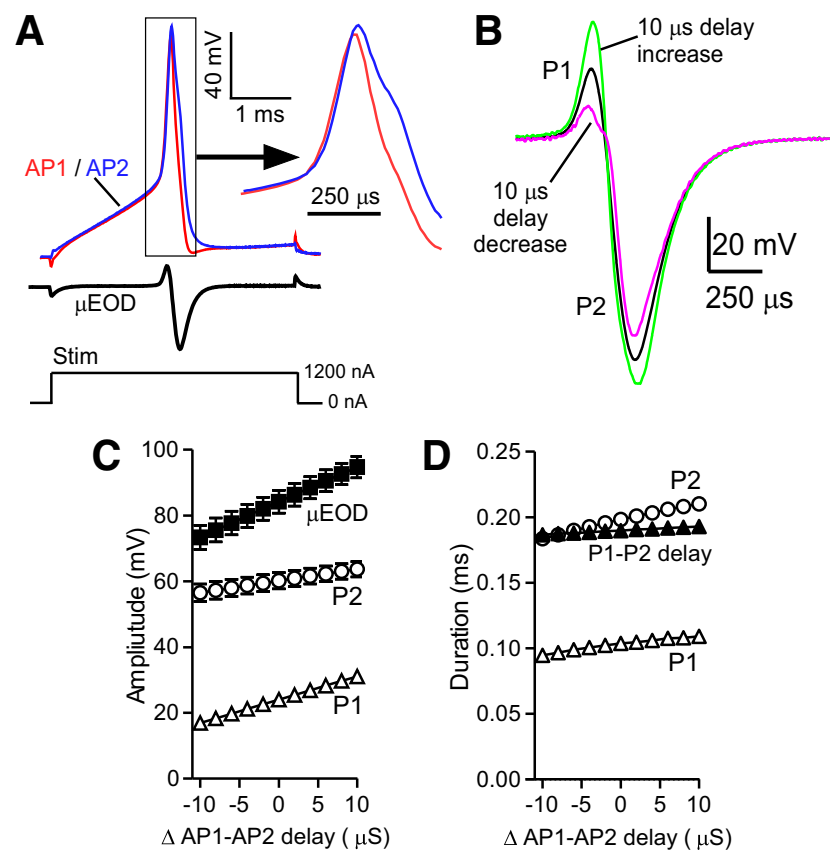

Figure 2. S. elegans electrocyte APs and simulations of $\mu \mathrm{EOD}$ distortion caused by changing AP1-AP2 delay. A, Superimposed recordings of AP1 (red) and AP2 (blue) show the close temporal relationship of the spikes. The resulting $\mu \mathrm{EOD}$ (black) is shown below. At right are the same waveforms in expanded timescale showing the slight delay between AP1 and AP2 onset and the broader waveform of AP2 with its characteristic shoulder during repolarization. $\boldsymbol{B}$, Summing digitized electrocyte AP waveforms while modifying AP1-AP2 delay shows that increasing or decreasing the AP1-AP2 delay by $10 \mu$ s distorts the $\mu$ EOD P1, First phase of $\mu \mathrm{EOD} ; \mathrm{P} 2$, second phase of $\mu \mathrm{EOD}$. Baseline is shown in black. C, Effects of changing AP1-AP2 delay on $\mu \mathrm{EOD}, \mathrm{P} 1$, and P2 amplitude. Experimentally recorded and digitized electrocyte AP1 and AP2 waveforms from six cells were summed across changes in the experimentally recorded AP1-AP2 delay ranging from -10 to $+10 \mu$ S. D, Simulations performed as in C, where P1 and P2 duration were measured at $50 \%$ of peak amplitude and P1-P2 delay was measured as the delay between the peaks of $\mathrm{P} 1$ and $\mathrm{P} 2$.

Electrocytes of S. elegans are encased in a sheath of tough connective tissue. To gain full access to the anterior and posterior electrocyte membranes, it was first necessary to incubate the electric organ for $30 \mathrm{~min}$ in 1 $\mathrm{ml}$ of normal saline containing $2 \%$ type IV collagenase (Worthington Biochemical), $1.25 \mathrm{mg}$ of elastase (Worthington Biochemical), and $0.5 \%$ bovine serum albumin (Sigma-Aldrich). The tissue was then rinsed 5 times over 20 min with normal saline containing $1 \%$ bovine serum albumin. Similar enzymatic treatment has been used to facilitate electric organ physiology in a related gymnotiform fish (Markham and Stoddard, 2005).

Loose-patch pipettes were filled with normal saline and had resistances of $0.7-1.2 \mathrm{M} \Omega$. For single-membrane recordings, a patch pipette was positioned on the anterior membrane or the posterior membrane. For simultaneous loose-patch recordings, one patch pipette was positioned on the anterior membrane and one on the posterior membrane. Pipettes were advanced gently against the membrane until $R_{\mathrm{S}}$ was equal to or greater than $R_{\mathrm{P}}$. To avoid "rim currents," the cell was then penetrated with two sharp intracellular pipettes and the intracellular potential was clamped to $-30 \mathrm{mV}$, thereby inactivating all transient ionic currents before proceeding with the loose-patch protocols (Almers et al., 1983; Roberts and Almers, 1984; Matavel et al., 2002). Using TEVC to clamp intracellular potential in this manner also maintained a known intracellular potential, allowing us to scale the patch pipette voltage commands precisely to achieve the desired membrane potential across each patch.

During loose-patch experiments, a Tucker-Davis RX8 real-time signal processor monitored the seal resistance and intracellular potential before each trial and then scaled the voltage-command waveforms in real-time 


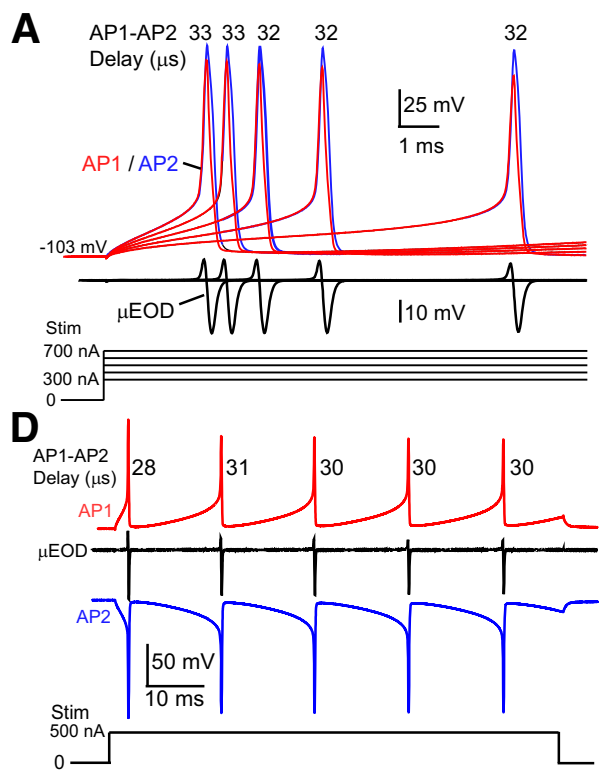

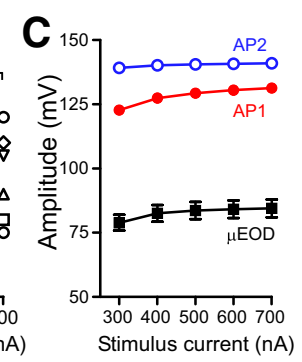

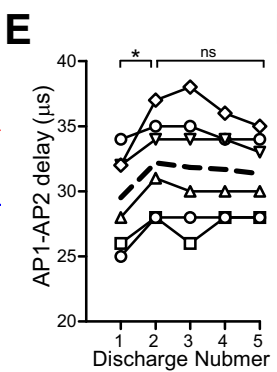

$\mathbf{F}$

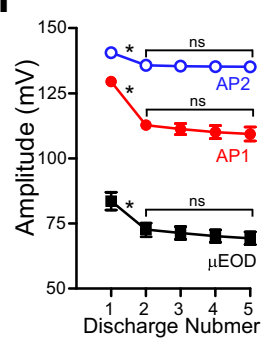

Figure 3. $A P$ and $\mu E O D$ characters across stimulus conditions. $A$, Voltage responses of an electrocyte to current steps from 300 to $700 \mathrm{nA}$ in $100 \mathrm{nA}$ increments. AP1 (red) and AP2 (blue) reach threshold after slow, uniform depolarization that is shortened by increasing stimulus intensity. The AP1-AP2 delay is indicated above the AP peaks for each condition. $\mu$ EOD waveform is shown below in black. $B, A P 1-A P 2$ delay across stimulus intensities for six cells, each cell denoted as a different symbol. Bold dashed line is the mean AP1-AP2 delay. There was no change in AP1-AP2 delay (repeated-measures ANOVA, $F_{(4,5)}=1.90, p=0.15$ ). $C$, Mean $(n=6)$ amplitude of AP1 (red) AP2 (blue) and $\mu$ EOD (black) for each stimulus intensity. At most data points, SEM error bars are hidden behind symbols. All three measures increased in a linear fashion with increased stimulus intensity (repeated-measures ANOVA, AP1 amplitude $F_{(4,5)}=100.8, p<0.0001 ;$ AP2 amplitude $F_{(4,5)}=22.08, p<0.0001 ; \mu$ EOD amplitude $F_{(4,5)}=87.63$, $p<0.0001)$. For all three measures, post hoc tests for linear trend were $p<0.0001$. D, Burst of five APs from a representative cell. AP2 (blue) is inverted to show temporal relation to AP1 (red) and $\mu$ EOD (black). AP1-AP2 delay is indicated next to AP1. $E$, AP1-AP2 delay for each of five discharges during a burst from six cells denoted by different symbols. Bold dashed line indicates the mean. Repeated-measures ANOVA revealed a significant difference only between the first and second discharges $\left(F_{(4,5)}=83.82\right.$, $p<0.0001$. Post hoc comparisons by Tukey's HSD for first vs second discharge: $q=7.318, p<0.001)$. $\boldsymbol{F}$, Mean $(n=6)$ amplitude of AP1 (red) AP2 (blue) and $\mu$ EOD (black) for each of 5 discharges during a burst. At most data points, SEM error bars are hidden behind symbols. All measures showed a decrease from the first to the second discharge, then remained unchanged thereafter (repeated-measures ANOVA, AP1 amplitude $F_{(4,5)}=30.73, p<0.0001 ; \mathrm{AP2}$ amplitude $F_{(4,5)}=43.45, p<0.0001 ; \mu \mathrm{EOD}$ amplitude $F_{(4,5)}=29.56, p<0.0001$; post hoc comparisons by Tukey's HSD for first vs second discharge: AP1 amplitude $q=$ $11.02, p<0.001 ;$ AP amplitude $q=13.73, p<0.001 ; \mu \mathrm{EOD}$ amplitude $q=10.21, p<0.001$ ).

to achieve the desired membrane potentials within the patch pipettes. Transmembrane holding potential was set at $-95 \mathrm{mV}$. Capacitative and leak currents were subtracted using a $\mathrm{p} / 6$ subtraction protocol. To prevent contamination of the $p / n$ leak subtraction by inward rectifier $\mathrm{K}^{+}$ currents $\left(I_{\mathrm{R}}\right)$ active near resting potential, all loose-patch recordings were performed in saline containing $100 \mu \mathrm{M} \mathrm{Ba}^{2+}$, which was sufficient to block $I_{\mathrm{R}}$ without significantly affecting AP waveform (see Fig. $4 D$ ).

Electrocyte model. For numerical simulations, the electrocyte was modeled as three cylindrical compartments arranged as a passive central compartment coupled to two flanking active compartments. External stimulation current was applied only to the central compartment, consistent with experimental procedure. The capacitance $C$ for each compartment was $10 \mathrm{nF}$, yielding a total membrane capacitance of $30 \mathrm{nF}$, which is consistent with empirical measurements of whole-cell capacitance. Differential equations were coded and integrated with MATLAB using Euler's method with integration time steps of $1 \times 10^{-9}$ to $1 \times$ $10^{-12} \mathrm{~s}$. All model parameters are shown in Table 1.

The passive central compartment's current balance equation included only terms representing the injected stimulation current pulses $I_{\text {Stim }}(t)$, passive leak $\left(I_{\mathrm{L}}\right)$ fixed at $15 \mu \mathrm{S}$, and coupling to the two active compartments as follows:

$$
C_{m} \frac{d V_{c}}{d t}=I_{\text {Stim }}(t)-I_{L}+g_{w}\left(V_{a}-V_{c}\right)+g_{w}\left(V_{p}-V_{c}\right)
$$

where $g_{\mathrm{w}}$ is the coupling conductance, which was fixed at $7 \mu \mathrm{S}$ for all compartments. The current balance equations for the anterior and posterior active compartments were, respectively:

$$
\begin{aligned}
C_{m} \frac{\mathrm{dV}}{\mathrm{dt}}=-\mathrm{I}_{\mathrm{Na}}-\mathrm{I}_{\mathrm{A}} & -\mathrm{I}_{\mathrm{K}}-\mathrm{I}_{\mathrm{R}}-\mathrm{I}_{\mathrm{L}} \\
& +g_{w}\left(V_{c}-V_{a}\right) \\
C_{m} \frac{\mathrm{dV}_{\mathrm{p}}}{\mathrm{dt}}=-\mathrm{I}_{\mathrm{Na}}-\mathrm{I}_{\mathrm{A}}- & \mathrm{I}_{\mathrm{K}}-\mathrm{I}_{\mathrm{R}}-\mathrm{I}_{\mathrm{L}} \\
& +g_{w}\left(V_{c}-V_{p}\right)
\end{aligned}
$$

where $I_{\mathrm{Na}}$ represents $\mathrm{Na}^{+}$current; $I_{\mathrm{A}}$ and $I_{\mathrm{K}}$ represent inactivating A-type and noninactivating delayed rectifier $\mathrm{K}^{+}$currents, respectively; IR is the inward rectifier $\mathrm{K}^{+}$current; and $I_{\mathrm{L}}$ is the leak current. Equations for these currents were as follows:

$$
\begin{gathered}
I_{N a}=\bar{g}_{N a} m^{3} h\left(V_{m}-50\right) \\
I_{A}=\bar{g}_{A} a^{3} b\left(V_{m}+100\right) \\
I_{K}=\bar{g}_{K} n^{4}\left(V_{m}+100\right) \\
I_{R}=\bar{g}_{R}\left(\frac{1}{1+\exp (0.1(V+95))}\right)\left(V_{m}+100\right) \\
I_{L}=\bar{g}_{L}\left(V_{m}+100\right)
\end{gathered}
$$

The gating variables in Equations $4-6$ are given by Equation 9, where $j=m, h, a, b$, or $n$ as follows:

$$
\frac{d j}{d t}=\frac{j_{\infty}\left(V_{m}\right)-j}{\tau_{j}\left(V_{m}\right)}
$$

The values of $j_{\infty}$ evolved in a voltage-dependent fashion as follows:

$$
j_{\infty}=\frac{1}{1+\exp \left(\frac{V 50_{j}-V_{m}}{k_{j}}\right)}
$$

where $V_{50 \mathrm{j}}$ and $k_{\mathrm{j}}$ are derived from Boltzmann sigmoidal fits to empirical data and are given in Table 1. $\tau_{\mathrm{j}}$ is given by Equation 11 for $j=a, b, m$, and $n$ as follows:

$$
\tau_{j}=\frac{\alpha_{j}}{1+\left(\frac{V_{m}-\mu_{j}}{\sigma_{j}}\right)^{2}}+\beta_{j}
$$

and by Equation 12 for $j=h$ as follows:

$$
\tau_{j}=\alpha_{j} \times \exp \left(-0.5 \times\left(\frac{V_{m}-\mu_{j}}{\sigma_{j}}\right)^{2}\right)+\beta_{j}
$$

where values of $\alpha_{\mathrm{j}}, \beta_{\mathrm{j}}, \mu_{\mathrm{j}}$, and $\sigma_{\mathrm{j}}$ were determined by least-squares best fits to empirical data and are given in Table 1.

\section{Results}

\section{Electrocyte passive properties and APs}

Cells had very hyperpolarized resting membrane potentials $(-107.1 \pm 0.76 \mathrm{mV})$ with input resistances of $26.5 \pm 2.4 \mathrm{k} \Omega$. Consistent with the cells' large size, membrane time constants 
were $0.92 \pm 0.05 \mathrm{~ms}$. Membrane capacitances, calculated from the measured time constants and resistances, were $35.6 \pm 2.8 \mathrm{nF}$.

Both AP spikes elicited by suprathreshold stimulation are brief and begin following a slow depolarization (Fig. 2A). AP2 was always broader (half-width $276 \pm 7 \mu$ s) than AP1 $(232 \pm 6$ $\left.\mu \mathrm{s} ; t_{(5)}=3.866, p=0.012\right)$. AP2 was higher in amplitude $(139.2 \pm 1.2 \mathrm{mV})$ than AP1 $\left(122.7 \pm 1.7 \mathrm{mV} ; t_{(5)}=7.122, p=\right.$ 0.0008; Fig. 2A). AP1 always occurred first, with a delay between the two AP peaks (AP1-AP2 delay) of $30 \pm 2 \mu \mathrm{s}$. The importance of tightly regulating the AP1-AP2 delay became apparent when we simulated changes in the AP1-AP2 delay by summing digitized AP waveforms (Fig. $2 B-D$ ). Advancing or delaying the onset of AP2 by just $10 \mu$ s severely alters the waveform of the resulting $\mu \mathrm{EOD}$.

We found that these AP characteristics were quite stable. When we delivered current steps from 300 to $700 \mathrm{nA}$ in $100 \mathrm{nA}$ increments, the APs and $\mu$ EODs initiated progressively earlier during the current step over a range of $\sim 5 \mathrm{~ms}$ (Fig. $3 A$ ), but the AP1-AP2 delay did not change and the amplitudes of AP1, AP2, and the $\mu \mathrm{EOD}$ increased only slightly (Fig. $3 B$ ). We also found that electrocytes fired bursts of APs during prolonged stimulation (Fig. 3D). This type of stimulation would never be encountered in physiological conditions, in which each electrocyte fires a single $\mu \mathrm{EOD}$ in response to each spinal command volley. However, we examined AP1-AP2 delay, AP amplitude, and $\mu \mathrm{EOD}$ amplitude during bursts of 5 APs elicited by $75 \mathrm{~ms}$ depolarizing current steps to determine how stable these parameters remain even during stimulus durations that would not occur in vivo. We found a small but significant increase in AP1-AP2 delay $(2.7 \pm$ $0.5 \mu \mathrm{s})$ between the first and second APs in the burst, then AP1AP2 delay remained unchanged during the ensuing APs (Fig. 3E). In a similar fashion, the amplitudes of $\mu \mathrm{EOD}, \mathrm{AP} 1$, and $\mathrm{AP} 2$ all decreased between the first and second spikes and then remained unchanged during the remaining APs in each burst (Fig. 3F).

Given this stability of the AP1-AP2 delay across these different stimulus regimes, we hypothesized that active ionic mechanisms could produce this microsecond-scale timing. We therefore proceeded to characterize the ionic currents present in S. elegans electrocytes.

\section{Ionic currents in S. elegans electrocytes}

TEVC recordings in normal saline revealed a pronounced inward rectifier $\mathrm{K}^{+}$current $\left(I_{\mathrm{R}}\right)$ that inactivates at $\sim-90 \mathrm{mV}$ (Figure $4 A, B)$. Bath application of $500 \mu \mathrm{M} \mathrm{Ba}^{2+}$ eliminated this inward rectification (Fig. 4C), increasing resting input resistance to $920 \pm 12 \mathrm{k} \Omega$. Resting potentials of cells in $\mathrm{Ba}^{2+}$ saline depolarized to $-79 \pm 4 \mathrm{mV}$, suggesting that the electrocyte's low resting potential results from a large $\mathrm{Ba}^{2+}$-sensitive $\mathrm{K}^{+}$conductance that sets resting potential at or near $E_{\mathrm{K}}$, possibly resulting from $I_{\mathrm{R}}$ in concert with other $\mathrm{Ba}^{2+}$-sensitive $\mathrm{K}^{+}$leak conductances.

The rapidly activating voltage-gated currents were very large $(>5 \mu \mathrm{A})$ and could not be adequately clamped even at the amplifier's maximum gain $(50 \mathrm{k} \mathrm{V} / \mathrm{V})$. Inadequate clamp precluded all quantitative analysis of the fast voltage-gated currents, but we were able to gain important qualitative data about these currents. In saline containing $100 \mu \mathrm{M} \mathrm{Ba}{ }^{2+}$, the addition of $1 \mu \mathrm{M}$ TTX eliminated all inward currents and further addition of $2 \mathrm{mM} 4 \mathrm{AP}$ with $50 \mathrm{~mm}$ TEA eliminated all voltage-dependent outward currents (data not shown), indicating the presence of voltage-gated $\mathrm{Na}^{+}$currents and at least two voltage-gated $\mathrm{K}^{+}$currents. By screening a large library of peptide $\mathrm{K}^{+}$channel toxins, we identified two that affected the outward $\mathrm{K}^{+}$currents. The sea anemone toxin ShK (from Stichodactyla helianthus; Kalman et al.,
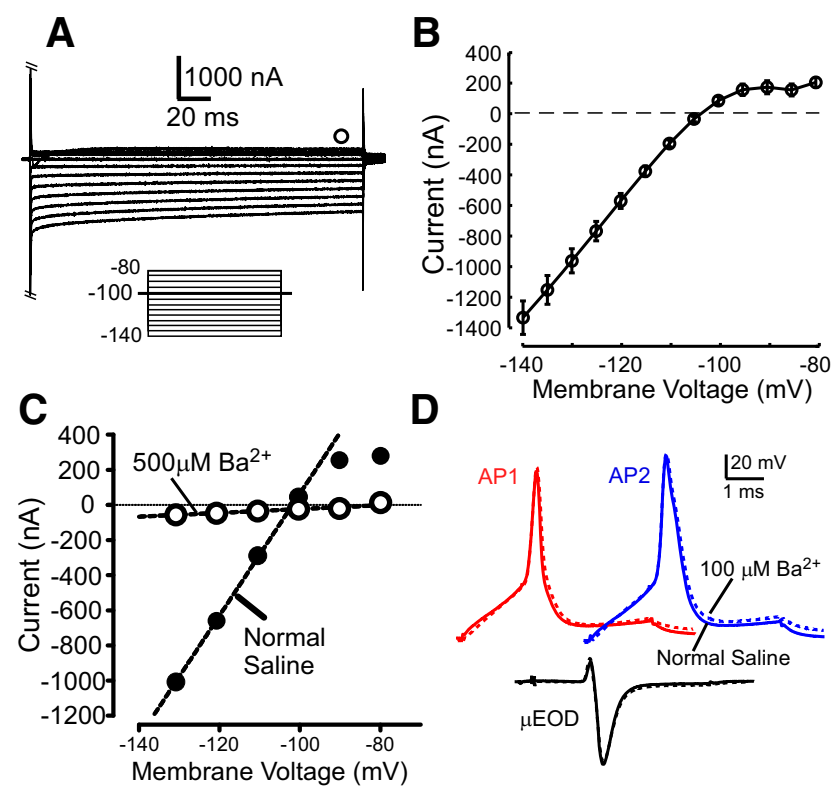

Figure 4. Electrocyte inward rectifier $\mathrm{K}^{+}$currents. $\boldsymbol{A}$, Representative family of currents from a cell stepped from $-140 \mathrm{mV}$ to $-80 \mathrm{mV}$ in $5 \mathrm{mV}$ increments. Open circle indicates the point where steady-state IV relationships are plotted in $\boldsymbol{B}$. Voltage command protocol is shown in inset. $\boldsymbol{B}$, IV data for six cells showing inward rectification at hyperpolarized potentials. $\boldsymbol{C}$, IV plots for three cells in normal saline and the same cells in saline containing $500 \mu \mathrm{m} \mathrm{Ba}{ }^{2+}$. Straight lines are linear fits of data points from -130 to $-100 \mathrm{mV}$; resistances are calculated from the slope of linear fits. $\boldsymbol{D}$, Application of $100 \mu \mathrm{M} \mathrm{Ba}^{2+}$ (the minimum concentration required to block inward rectification and the concentration used during loose-patch-clamp recordings) produced only slight broadening of both $A P 1$ and $A P 2$, indicating that its effect on remaining voltage-gated $\mathrm{K}^{+}$currents is minimal.

1998; Yan et al., 2005) selectively and irreversibly eliminated only the inactivating component of the outward currents and the $\mathrm{K}^{+}$ channel blocker Tityustoxin (Eccles et al., 1994) eliminated the remaining outward currents (data not shown).

To characterize these currents quantitatively and localize them to the anterior or posterior membranes, we performed cellattached loose patch recordings on the posterior or anterior membranes. Patch currents from both membranes in normal saline with $100 \mu \mathrm{M} \mathrm{Ba}^{2+}$ showed three voltage-dependent components: a TTX-sensitive inward current and outward currents with an inactivating early component and a persistent late component (Fig. 5A).

In the presence of $1 \mu \mathrm{M}$ TTX, the remaining outward currents retained a rapidly inactivating early component and a persistent late component. We found that ShK (50 nM) selectively blocked the inactivating component of the outward current, isolating a delayed-rectifier $\mathrm{K}^{+}$current $\left(\mathrm{I}_{\mathrm{K}}\right.$; Fig. $\left.5 B, D\right)$. Subtraction of the delayed rectifier current family from records of total outward current yielded a rapidly activating/inactivating A-type $\mathrm{K}^{+}$current $\left(I_{\mathrm{A}}\right.$; Fig. $\left.5 C, D\right)$. Because we had limited access to subject animals for electric organ tissue, we did not record $\mathrm{K}^{+}$currents from enough cells to allow a full quantitative analysis. We chose instead to focus on a thorough characterization of the electrocyte's voltage-gated $\mathrm{Na}^{+}$currents, hypothesizing that differences in threshold were associated with differences in $I_{\mathrm{Na}}$ between the two membranes.

Simultaneous loose-patch recordings from the posterior and anterior membranes in the presence of $100 \mu \mathrm{M} \mathrm{Ba}{ }^{2+}, 1 \mu \mathrm{M}$ Tityustoxin, and $50 \mathrm{~nm}$ ShK showed only a transient inward $\mathrm{Na}^{+}$ current with no outward $\mathrm{K}^{+}$currents (Fig. $6 A$ ). To ensure accurate and consistent voltage control on both patches, we selected 


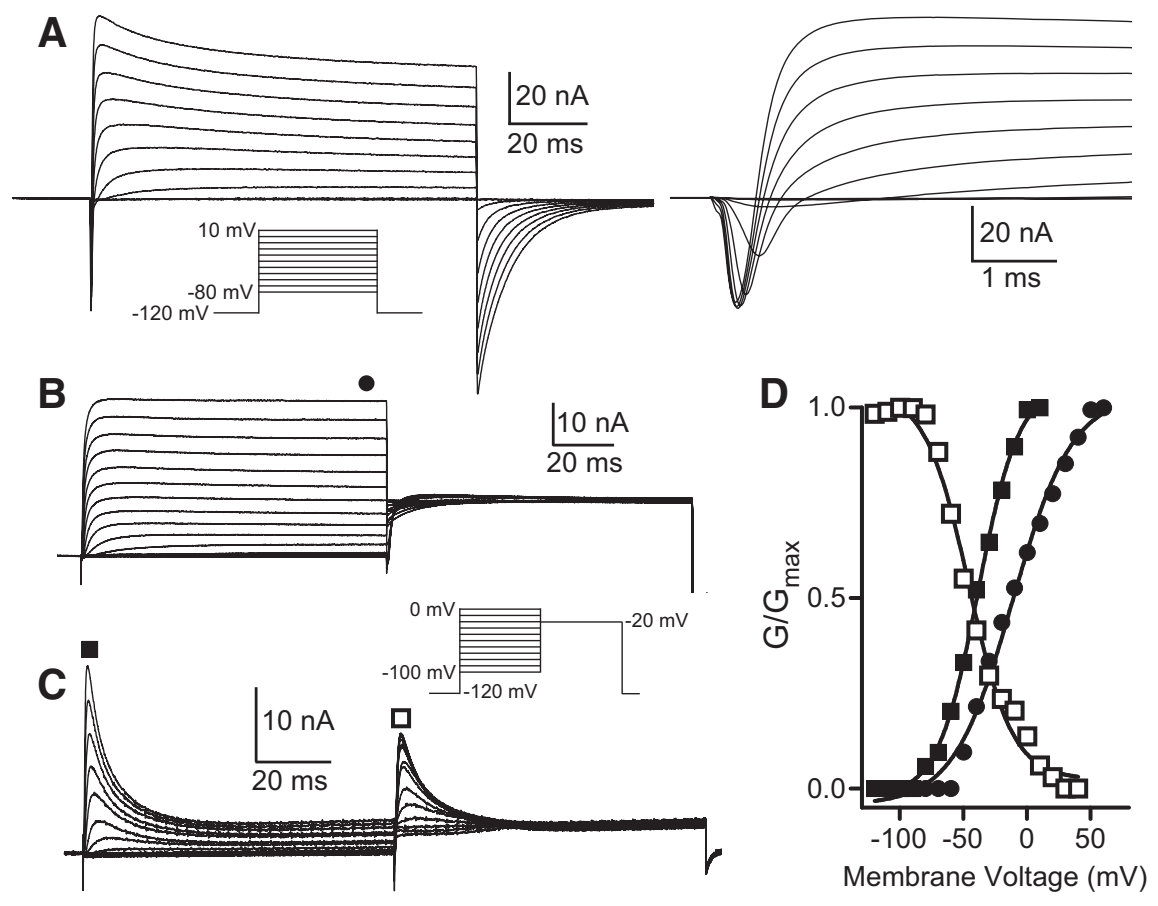

Figure 5. Total voltage-gated posterior membrane currents and isolation of distinct $\mathrm{K}^{+}$currents. $A$, Currents elicited by voltage steps from -80 to $10 \mathrm{mV}$ show three voltage-dependent components, a transient inward current followed by an inactivating outward current and a persistent outward current. Inset shows voltage command protocol. Current family at right is the same set of traces on an expanded timescale to show the transient inward component. $\boldsymbol{B}$, Currents recorded in $1 \mu \mathrm{m} \mathrm{TTX} \mathrm{and} 50 \mathrm{~nm}$ ShK show an isolated delayed-rectifier $\mathrm{K}^{+}$current $\left(I_{\mathrm{K}}\right)$. Voltage command protocol is shown in the inset. Filled black circle shows where steady-state IV relationships are plotted in $\boldsymbol{D}$. C, Subtraction of $I_{K}$ currents from total outward currents recorded in $1 \mu \mathrm{m}$ TTX reveal an inactivating A-type $\mathrm{K}^{+}$current $\left(I_{\mathrm{A}}\right)$. Voltage command protocol is shown in inset. Filled black box shows where activation IV relationships are plotted in $\boldsymbol{D}$ and open black box shows where inactivation IV relationships are plotted in $\boldsymbol{D}$. Voltage command protocol as in $\boldsymbol{B}$. $\boldsymbol{D}$, Activation (filled boxes) and inactivation (open boxes) IV curves for $I_{A}$. Filled circles show the activation IV curve for $I_{K}$.

only recordings in which the $I_{\mathrm{Na}}$ reversal potential was the same for both anterior and posterior patches.

Posterior membrane $\mathrm{Na}^{+}$channels activated at potentials $\sim 10 \mathrm{mV}$ more hyperpolarized than anterior membrane $\mathrm{Na}^{+}$ channels (Fig. $6 B$ ), but there was no difference in the voltage dependence of inactivation (Fig. $6 B$ ). We found that voltage dependence of the activation time constant also was shifted in the hyperpolarized direction for $\mathrm{Na}^{+}$channels on the posterior membrane (Fig. 6C). This difference in the tau- $\mathrm{V}$ relation could be a function of the hyperpolarized activation of posterior membrane $\mathrm{Na}^{+}$channels. We therefore compared activation tau as a function of the proportion of open channels (Fig. $6 D)$ and found no difference between the posterior and anterior $\mathrm{Na}^{+}$channels. The same was true for $\mathrm{Na}^{+}$channel inactivation-the tau-V curve was shifted in the hyperpolarizing direction for posterior-membrane $\mathrm{Na}^{+}$channels (Fig. 6E), but there was no difference between the posterior and anterior membrane channels for inactivation tau as a function of channel open probability (Fig. $6 F$ ).

Recovery from inactivation proceeded with both slow and fast components for both posterior and anterior membrane $\mathrm{Na}^{+}$ channels. There was no difference in the slow component of $I_{\mathrm{Na}}$ recovery between posterior and anterior membrane $\mathrm{Na}^{+}$channels (Fig. 7A). However, the fast recovery component proceeded with a shorter time constant for posterior membrane $\mathrm{Na}^{+}$channels than for anterior membrane $\mathrm{Na}^{+}$channels (Fig. 7B).

\section{Numerical simulations show that differences in $I_{\mathrm{Na}}$ activation voltage are sufficient to maintain AP1-AP2 delay in the microsecond domain}

To investigate whether the observed difference in activation voltage between posterior and anterior membrane $\mathrm{Na}^{+}$ channels is sufficient to maintain the AP1-AP2 delay, we performed computational simulations of electrocyte APs and $\mu$ EODs. Our model electrocyte included a passive central compartment flanked by two active compartments (posterior and anterior). Each of the active compartments had identical $I_{\mathrm{R}}, I_{\mathrm{K}}$, and $I_{\mathrm{A}}$. We varied only the maximum conductance for each of these currents. The parameters for these currents were derived from our experimental recordings of these currents and were adjusted so that simulated voltage-clamp currents corresponded well with these currents as measured in our TEVC and loose-patch experiments.

Each active compartment also had $I_{\mathrm{Na}}$ with parameters derived from our characterization of these currents. Only two parameters were different between the anterior and posterior compartment $\mathrm{Na}^{+}$ current $\left(I_{\mathrm{NaA}}\right.$ and $I_{\mathrm{NaP}}$, respectively). The activation $V_{50}$ was hyperpolarized for $I_{\mathrm{NaP}}$ : we used the exact values of $V_{50}$ from our empirical measurements of these currents (anterior, $-54.20 \mathrm{mV}$; posterior, $-64.12 \mathrm{mV}$ ). The second parameter that differed between the two compartments was $\alpha_{h}$ (anterior, $1.653 \mathrm{~ms}$; posterior $0.753 \mathrm{~ms}$ ), a difference that shifts the inactivation tau- $\mathrm{V}$ function in the hyperpolarized direction for posterior $\mathrm{Na}^{+}$currents, which is consistent with our empirical data (Fig. 6C). Differences in these two parameters were also essential for the model to faithfully reproduce the $\mathrm{Na}^{+}$currents recorded from our loose-patch recordings in vitro (cf. Figs. $8 D$, $6 A)$.

Simulated whole-cell currents, $I_{\mathrm{K}}$, and $I_{\mathrm{A}}$ (Fig. 8A-C), corresponded very closely to loose-patch recordings of these same currents in vitro (Fig. $5 A-C$ ). There was also strong correspondence between simulated $\mathrm{Na}^{+}$currents (Fig. $8 D$ ) and $\mathrm{Na}^{+}$currents recorded experimentally (Fig. $6 A$ ).

We then simulated responses of the model electrocyte in current-clamp conditions. During all simulations, changes in the maximum conductance for $I_{\mathrm{K}}$ had no effect on the overall model output, because this current activated mildly only near the peak of the AP. In contrast, small changes in $I_{\mathrm{A}}$ conductance had profound impacts on the simulation outputs. Accordingly, we left the $I_{\mathrm{K}}$ conductance fixed at $500 \mu \mathrm{S}$ for both active compartments in all simulations shown here. We used our model electrocyte to test several plausible hypotheses for the ionic mechanisms that maintain the AP1-AP2 delay while keeping AP2 broader than AP1.

We began by simulating a cell in which the voltage dependence of $I_{\mathrm{NaA}}$ and $I_{\mathrm{NaP}}$ were identical $(-54.20 \mathrm{mV})$. When the conductance magnitudes of all voltage-gated currents were the same (Fig. 9A), AP1 and AP2 were therefore identical and the 

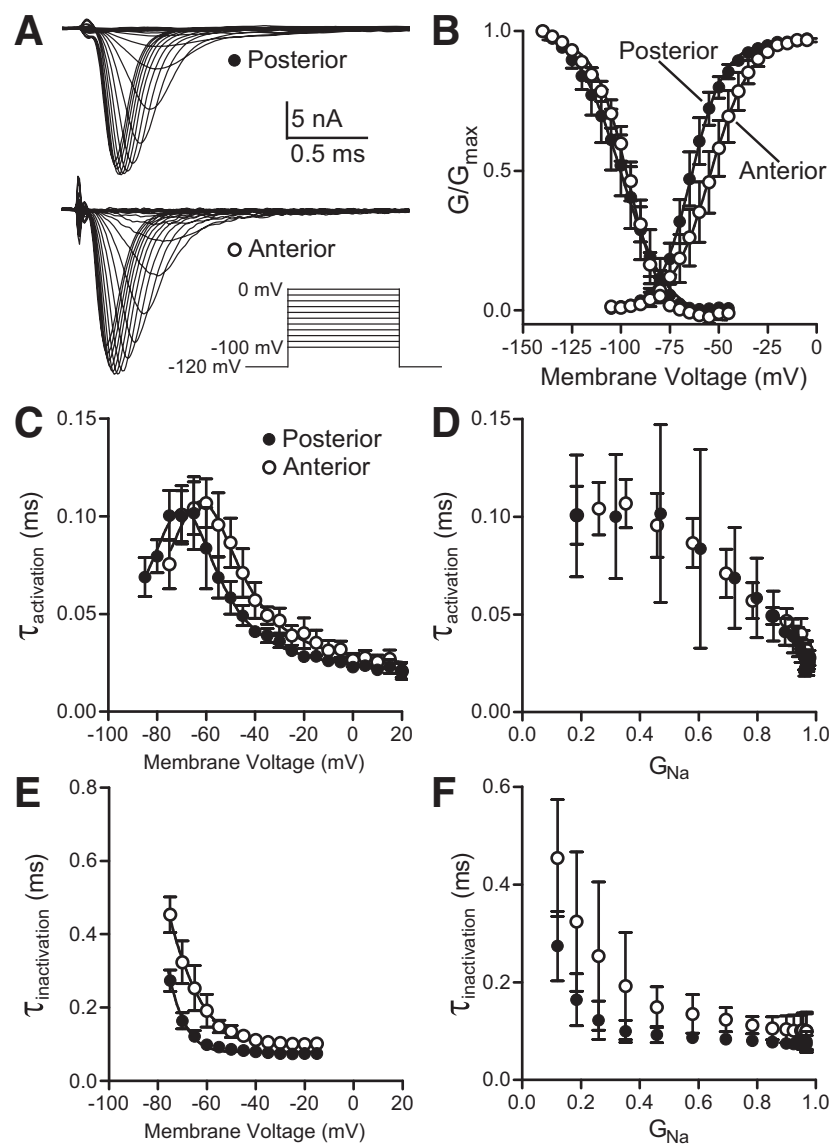

Figure 6. Characteristics of $S$. elegans electrocyte $\mathrm{Na}^{+}$currents. For all plots, open circles denote anterior membrane patches and closed circles denote posterior membrane patches. $\boldsymbol{A}$, Representative $I_{\mathrm{Na}}$ patch currents from the posterior membrane (top) and anterior membrane (bottom) in response to voltage steps from $-100 \mathrm{to} 0 \mathrm{mV}$ in $5 \mathrm{mV}$ increments. Inset is the voltage command protocol. $\boldsymbol{B}$, Activation and inactivation IV plots for ${ }_{\mathrm{Na}}$ recorded from anterior and posterior membrane patches. Solid lines are Boltzmann sigmoidal fits. There was no difference in voltage dependence of $I_{\mathrm{Na}}$ inactivation between anterior and posterior membrane patches (repeated-measures ANOVA, interaction $F_{(1,19)}=0.6491, p=0.863$ ). There was a hyperpolarizing shift of $10 \mathrm{mV}$ in the activation voltage of $I_{\mathrm{NaP}}$ Compared with $I_{\text {NaA }}$ (repeatedmeasures ANOVA, interaction $\left.F_{(1,25)}=2.40, p=0.0003\right), C, I_{\mathrm{Na}}$ activation $\tau$-V curves for anterior and posterior membrane patches. Solid lines are Lorentzian fits. The apparent hyperpolarizing shift in activation $\tau$ for $I_{\text {Nap }}$ was not statistically significant (repeated-measures ANOVA, interaction $\left.F_{(1,17)}=1.101, p=0.356\right)$. Even a far less conservative comparison by paired $t$ test at $-50 \mathrm{mV}$, the point of greatest apparent difference, indicates no significant difference $\left(t_{(5)}=1.904, p=0.1152\right) . \boldsymbol{D}, I_{\mathrm{Na}}$ activation $\tau$ as a function of relative $\mathrm{Na}^{+}$conductance. $E, I_{\mathrm{Na}}$ inactivation $\tau$-V curves for anterior and posterior membrane patches. Solid lines are Gaussian fits. Inactivation $\tau$ was hyperpolarized for $I_{\text {NaP }}$ compared with $I_{\text {NaA }}$ (repeatedmeasures ANOVA, interaction $\left.F_{(1,14)}=3.422, p=0.0002\right) . F_{,} I_{\mathrm{Na}}$ inactivation $\tau$ as a function of relative $\mathrm{Na}^{+}$conductance.

resulting $\mu \mathrm{EOD}$ (calculated by subtraction of AP2 from AP1) was absent. We then tested whether a higher conductance magnitude for $I_{\mathrm{A}}$ on the anterior membrane $\left(I_{\mathrm{AA}}\right)$ could contribute to the AP1-AP2 delay by delaying the onset of AP2 (Fig. 9B). This model did produce an appropriate AP1-AP2 delay, but it also narrowed AP2 such that the resulting $\mu \mathrm{EOD}$ was monophasic and distorted (Fig. 9B). A second possible mechanism for the AP1-AP2 delay is a higher conductance magnitude for $I_{\mathrm{Na}}$ on the posterior membrane $\left(g_{\mathrm{NaP}}\right)$ than on the anterior membrane $\left(g_{\mathrm{NaA}}\right)$. We tested this hypothesis in a model in which the posterior membrane had nearly twice the $\mathrm{Na}^{+}$conductance magnitude as the anterior membrane, with other conductances held equal. Again, this model produced an appropriate AP1-AP2 de-
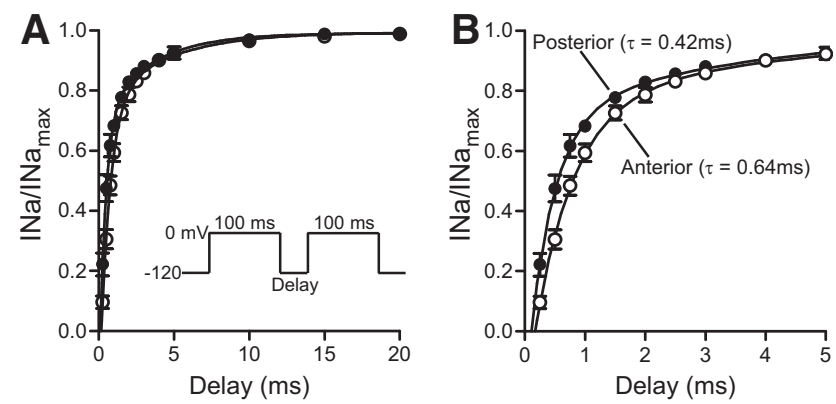

Figure 7. $I_{\mathrm{Na}}$ recovery from inactivation. $A$, Time dependence of $I_{\mathrm{Na}}$ recovery from inactivation for anterior membrane patches (open circles) and posterior membrane patches (filled circles). Lines represent double exponential fits. Inset is the command protocol. Pairs of $100 \mathrm{~ms}$ steps from -120 to $0 \mathrm{mV}$ were separated by steps to $-120 \mathrm{mV}$ that increased from 0.25 to 20 ms. $\boldsymbol{B}$, Same data as in $\boldsymbol{A}$ on an expanded time scale. Solid lines represent single exponential fits. The fast recovery component was faster for $I_{\text {NaP }}$ than for $I_{\text {NaA }}$ (repeated-measures ANOVA, interaction $\left.F_{(1,14)}=6.156, p<0.0001\right)$.

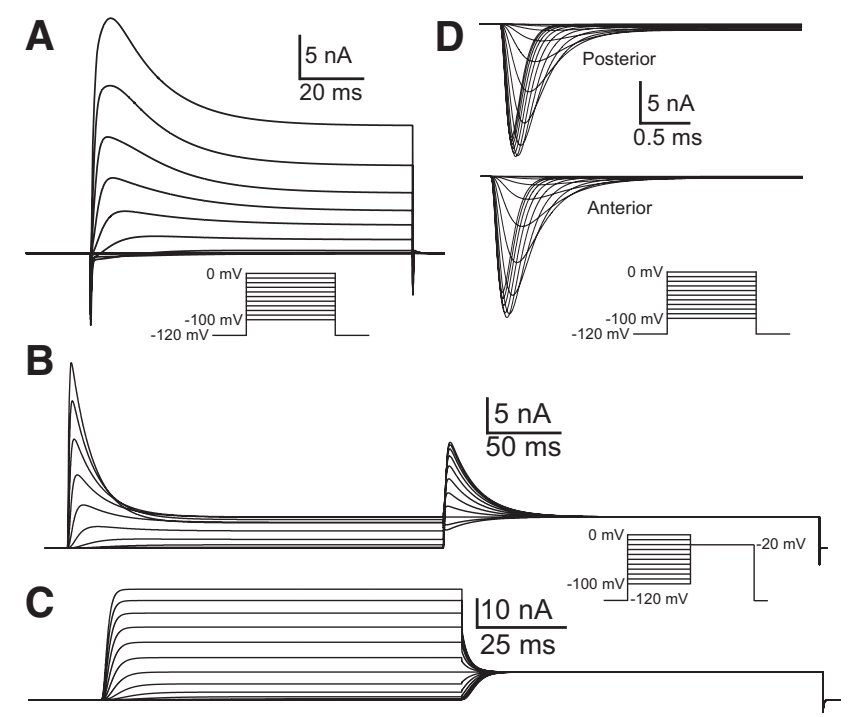

Figure 8. Simulations of electrocyte $\mathrm{Na}^{+}$and $\mathrm{K}^{+}$currents. Compare with experimental data in Figures 5 and 6 . Insets show voltage command protocols. $A$, Simulated total membrane currents evoked by depolarizing steps from a holding potential of $-120 \mathrm{mV}$ to potentials ranging from -100 to $0 \mathrm{mV}$ in $10 \mathrm{mV}$ increments. $\boldsymbol{B}$, Simulated $I_{\mathrm{A}}$ currents evoked by steps from -100 to $0 \mathrm{mV}$ in $10 \mathrm{mV}$ increments followed by a step to $-20 \mathrm{mV}$. C, Simulated $I_{\mathrm{K}}$ currents in response to the same voltage command protocol as in $\boldsymbol{B}$. D, Simulations of posterior and anterior membrane $I_{\mathrm{Na}}$ evoked by voltage steps from -100 to $0 \mathrm{mV}$ in $5 \mathrm{mV}$ increments.

lay, but AP1 was broader than AP2 so the resulting $\mu \mathrm{EOD}$ was monophasic (Fig. 9C). We then increased the conductance magnitude for $I_{\mathrm{A}}$ on the posterior membrane $\left(g_{\mathrm{AP}}\right)$ to shorten AP1. Doing so, however, began to diminish the AP1-AP2 delay just as AP1 width began to exceed the width of AP2 (Fig. 9D).

In contrast, when we modeled the electrocyte with our experimentally determined voltage dependences for $I_{\mathrm{NaA}}$ and $I_{\mathrm{NaP}}$ activation $\left(V_{50}=-54.20\right.$ and $-64.12 \mathrm{mV}$, respectively) the resulting AP1-AP2 delay, AP waveforms, and $\mu \mathrm{EOD}$ waveform were significantly improved (Fig. 9E). Surprisingly, this difference alone was sufficient to approximate well the AP timing and $\mu \mathrm{EOD}$ waveform even when all other parameters and current densities were the same between compartments. The model was improved further by decreasing $g_{\mathrm{A}}$ on the anterior compartment $\left(g_{\mathrm{AA}}\right)$, a change that broadened AP2 in accordance with our experimental data. This final model produced the best correspon- 


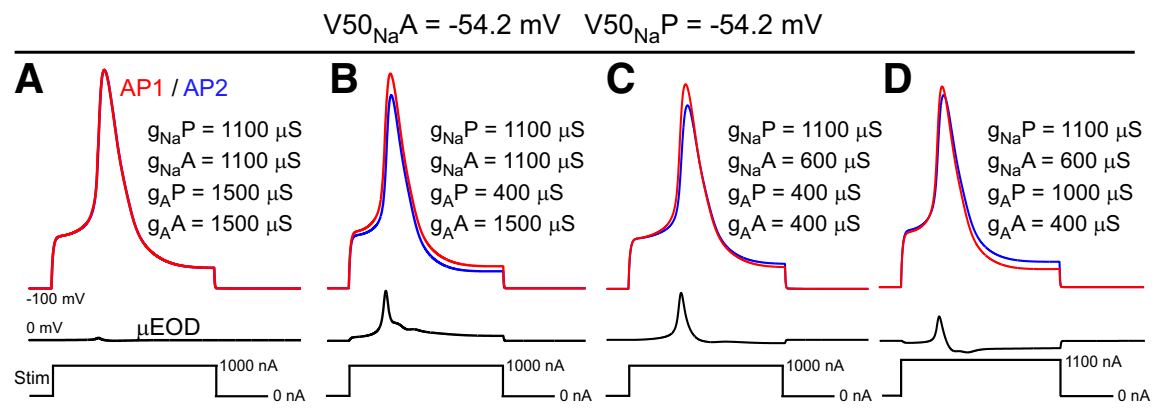

$\mathrm{V} 50_{\mathrm{Na}} \mathrm{A}=-54.2 \mathrm{mV} \quad \mathrm{V} 50_{\mathrm{Na}} \mathrm{P}=-64.1 \mathrm{mV}$

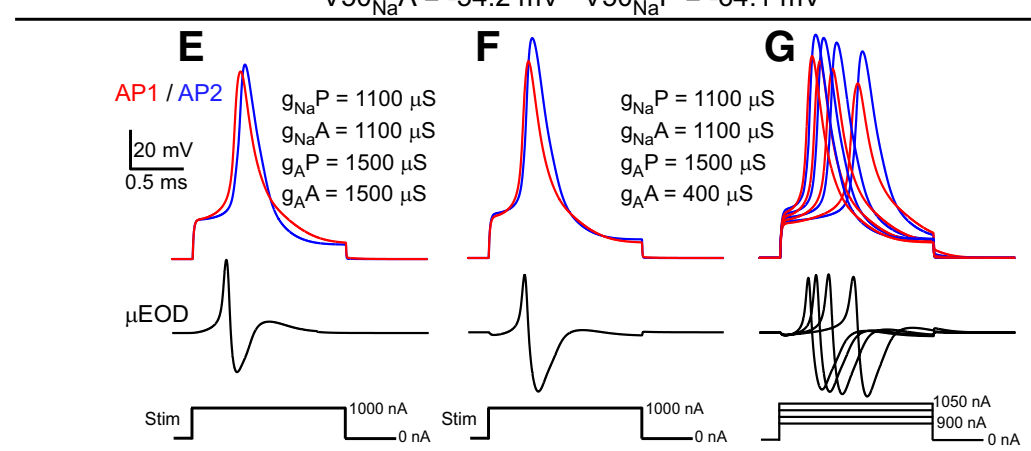

Figure 9. Simulated APs and $\mu$ EODs elicited by 1.5 ms depolarizing current steps. AP1 is shown in red, AP 2 in blue, with $\mu E 0 D$ in black below. The stimulus waveform is shown below the $\mu \mathrm{EOD}$. In $\boldsymbol{A}-\boldsymbol{D}, I_{\mathrm{Na}}$ activation voltage was identical in the posterior and anterior compartments, whereas in $\boldsymbol{E}-\mathbf{G}, I_{\mathrm{Na}}$ activation voltage was hyperpolarized for the posterior compartment. $\boldsymbol{A}$, When conductance magnitudes are identical for both compartments, the two APs are simultaneous and nearly identical. $\boldsymbol{B}$, Decreasing $g_{\mathrm{A}}$ on the posterior compartment $\left(g_{\mathrm{AP}}\right)$ advances the onset of AP1, but makes AP1 broader than AP1, creating a positive going monophasic $\mu$ EOD. C, Reducing $g_{\mathrm{NaA}}$ relative to $g_{\mathrm{NaP}}$ also is sufficient to advance the onset of AP1 ahead of AP2. A reduction of $g_{\mathrm{AA}}$ was necessary for the reduced $I_{\mathrm{NaA}}$ to bring the anterior compartment to threshold. The resulting $\mu \mathrm{EOD}$ remains monophasic because the durations of AP1 and AP2 are similar. $\boldsymbol{D}$, Increasing $g_{\text {AP }}$ shortens AP1 and introduces a low-amplitude negative phase to the $\mu \mathrm{EOD} . \boldsymbol{E}$, When the I $_{\mathrm{NaP}}$ activation voltage was hyperpolarized in accordance with experimental data, our model electrocyte exhibited appropriate AP1-AP2 delay and produced a biphasic $\mu E 0 D$, even when all conductance magnitudes were equal. $\boldsymbol{F}$, Modifying the model from $\boldsymbol{E}$ by reducing $g_{\mathrm{AA}}$ broadened AP2 in accordance with experimental data and produces the best-fit simulated $\mu$ EOD that closely resembles experimental data. $\mathbf{G}$, Same model as in $\boldsymbol{F}$, with APs elicited by depolarizing current steps from 900 to $1050 \mathrm{nA}$ in $50 \mathrm{nA}$ increments. The responses of this model show the maintenance of AP1-AP2 delay and $\mu$ EOD waveform across stimulus intensities, which is consistent with experimental data.

dence between simulated and experimentally recorded APs and $\mu$ EODs (Fig. $9 F$ ). Importantly, this model also reproduced our experimental observations that the AP1-AP2 delay and AP waveforms do not change across a range of stimulus intensities, thus preserving $\mu \mathrm{EOD}$ waveform.

With additional simulations, we evaluated whether other proposed mechanisms for the AP1-AP2 delay could produce comparable results without relying on differences in $I_{\mathrm{Na}}$ properties between the anterior and posterior compartments. In particular, one of the earliest proposed mechanisms for the AP1-AP2 delay was that differences in membrane resistance could be responsible for a faster depolarization of the posterior compartment than for the anterior compartment (Bennett, 1961). This difference could arise from a higher leak conductance or a higher $I_{R}$ conductance on the anterior membrane. We tested these possibilities with a model electrocyte in which the voltage dependence of $I_{\mathrm{NaA}}$ and $I_{\mathrm{NaP}}$ were identical $(-54.20 \mathrm{mV}$; Fig. $10 A, B)$. We found that significantly increasing the $I_{\mathrm{R}}$ conductance on the anterior compartment $\left(g_{\mathrm{RA}}\right)$ did produce a reasonably appropriate AP1-AP2 delay, but the composite $\mu \mathrm{EOD}$ waveform was significantly distorted and the AP1-AP2 delay decreased as stimulus intensity increased (Fig. 10A), an outcome inconsistent with experimental data (cf. Fig. $3 A$ ).

Increasing the leak conductance on the anterior compartment $\left(g_{\mathrm{LA}}\right)$ was sufficient to produce an appropriate AP1-AP2 delay
(Fig. 10B) and the AP1-AP2 delay was well maintained across different stimulus intensities. In addition, these simulations corresponded fairly well with experimental data, with a simulated $\mu$ EOD that approximated the $\mu \mathrm{EOD}$ recorded in vitro. However, this model showed a key discrepancy with our experimental data. In response to the step current stimulus, the slow depolarization ahead of the APs proceeded at different rates for the posterior and anterior compartments (Fig. 10C, arrow). Electrocyte APs recorded in vitro show a uniform slow depolarization before reaching threshold (Fig. 2A). This behavior is best reproduced by the electrocyte model with identical anterior and posterior compartment leak conductances and different voltage dependences of $I_{\mathrm{NaA}}$ and $I_{\mathrm{NaP}}$ (Figs. $10 D, 9 F, G$ ).

\section{Discussion}

The central finding of this study is that differences in the activation voltage of $\mathrm{Na}^{+}$channels between two cellular compartments is sufficient to determine both the location and the timing of AP initiation in S. elegans electrocytes. This mechanism ensures that the posterior membrane always fires before the anterior membrane regardless of stimulus intensity and maintains a precise delay between these two APs.

The temporal precision of AP timing in S. elegans electrocytes is particularly striking. The AP1-AP2 delay is on the order of $\sim 30 \mu$ s and varies by just a few microseconds across a range of stimulus conditions. One of earliest hypotheses for the reliable AP1-AP2 delay in electrocytes from S. elegans and related species was that passive differences between the two active membranes were responsible for controlling AP order and timing (Bennett, 1961). In particular, greater resistance on the innervated posterior membrane would lead to faster voltage change on this face for the same amount of synaptic current, causing the AP to initiate first on this membrane. These mechanisms remain as plausible contributors to the maintenance of AP timing in electrocytes. The data we report here demonstrate an additional mechanism responsible for AP timing in this system: electrocytes' active ionic conductances can regulate the location and timing of AP initiation with microsecond precision. These findings have important implications for understanding both the precise maintenance of AP1-AP2 delay in S. elegans and the precise modulation of AP1-AP2 delay over the course of minutes in related species that rapidly modulate EOD waveform in response to social and circadian cues (Markham and Stoddard, 2005).

Sensitivity to microsecond-scale timing differences is necessary for processing interaural time differences in the vertebrate CNS (Brand et al., 2002; Jercog et al., 2010; Funabiki et al., 2011), for processing electrosensory signals in weakly electric fish (Matsushita and Kawasaki, 2005), and for the stability of highfrequency pacemaker circuits (Moortgat et al., 1998). In these 
cases, the coding of microsecond-scale information is performed by ensembles of many cells relying on both intrinsic and synaptic mechanisms. Our present results demonstrate a cell-autonomous mechanism for managing neural events on the microsecond scale shaped by functional properties of ion channels.

Our findings are also important for understanding general principles that govern the location of AP initiation. The need to reliably initiate the AP in a particular cellular compartment is common across taxa and across different classes of excitable cells. In electrocytes and central neurons, different evolutionary pressures have selected $\mathrm{Na}^{+}$channel voltage dependence as a mechanism for controlling the location and timing of AP initiation, probably modifying different molecular classes of $\mathrm{Na}^{+}$channels in two different cell types to do so. In certain classes of cortical pyramidal neurons, differences in voltage dependence of Nav1.2 and Nav1.6 channels between the soma and AIS help to ensure that APs are reliably initiated in the AIS (Colbert and Pan, 2002; Hu et al., 2009). In electrocytes, the same mechanism is at work, likely using different $\mathrm{Na}^{+}$ channel isoforms. To date, the only voltage-gated $\mathrm{Na}^{+}$channels detected in $S$. elegans electrocytes are Nav1.4 channels (Zakon et al., 2006; Arnegard et al., 2010). The evolution of electrocytes with dual active membranes appears to have been driven, at least in part, by predation pressures. The biphasic $\mu \mathrm{EOD}$ produced by electrocytes such as those of $S$. elegans requires the rapid succession of two APs in each electrocyte (Bennett, 1961), an adaptation that suppresses low-frequency signal energy and thus conceals the EOD from electroreceptive predators (Stoddard, 1999; Stoddard and Markham, 2008).

From a different perspective, electrocytes and central neurons share the common role of encoding and transmitting information, with central neurons encoding and transmitting information within neural systems and electrocytes encoding and transmitting information between individuals. AP frequency is a key carrier of information in neural systems and EOD rate is equally important for interspecific communication. However, AP waveform also plays an important role for information coding in the CNS (de Polavieja et al., 2005; Alle and Geiger, 2006, 2008), just as the EOD waveform is an important information carrier. For electric fish, EOD waveforms encode static information such as species, sex, and individual identity (Hopkins and Bass, 1981; Friedman and Hopkins, 1998), as well as dynamic information such as social status, reproductive status, and body condition (Salazar and Stoddard, 2009; Gavassa et al., 2011; Gavassa et al., 2013), demonstrating the ecological importance of mechanisms that regulate electrocytes' $\mu$ EOD microstructure.

Given the large whole-cell currents generated by electrocytes of several species, recent experimental data and computational simulations suggest that the energetic demand of electrocyte APs can be orders of magnitude larger than for central neurons (Markham et al., 2013; Lewis et al., 2014). As a result of 10002000 electrocytes firing simultaneously to produce the EOD, this signal production can consume up to $30 \%$ of the animal's daily energy budget (Salazar and Stoddard, 2008; Salazar et al., 2013). Simulations from our final model of the S. elegans electrocyte predict that the integrals of $I_{\mathrm{NaP}}$ and $I_{\mathrm{NaA}}$ are $0.91 \mu \mathrm{A}^{\star} \mathrm{ms}$ and 0.64 $\mu \mathrm{A}^{\star} \mathrm{ms}$, respectively, producing a combined influx of $9.76 \times 10^{9}$ $\mathrm{Na}^{+}$ions per $\mu$ EOD and a predicted energy expenditure of $3.25 \times 10^{9}$ ATP per $\mu$ EOD. This value is approximately an order of magnitude lower than the energetic cost per $\mu \mathrm{EOD}$ recently measured from another electric fish, Eigenmannia virescens $\left(2.2 \times 10^{10}\right.$ ATP per AP; Lewis et al., 2014). E. virescens electrocytes have only one excitable membrane, producing a single AP that yields a monophasic EOD. Therefore, although it might be predicted that the overlapping APs in S. elegans electrocytes would decrease the energy efficiency of the composite $\mu \mathrm{EOD}$ compared with E. virescens, our simulations do not support this conclusion. This is most likely because the APs of $S$. elegans electrocytes are of much shorter duration than those of E. virescens and because S. elegans 
electrocytes are smaller than those of E. virescens, which can approach $1 \mathrm{~mm}$ in length (Markham et al., 2013).

We do not yet know what mechanisms determine the differences in $\mathrm{Na}^{+}$channel activation voltage observed in this study. One possibility is that different $\mathrm{Na}^{+}$channel isoforms are expressed on the anterior and posterior membranes. Functional $\mathrm{Na}^{+}$channels typically consist of one pore-forming $\alpha$-subunit and one or two auxiliary $\beta$-subunits. Available evidence suggests that all gymnotiform electrocytes express two $\mathrm{Na}^{+}$channel $\alpha$-subunit genes, Nav1.4a and Nav1.4b, with NaV1.4b having two splice variants (Zakon et al., 2006; Liu et al., 2008). Differences in relative expression of these channel genes have to date been associated with alterations of $I_{\mathrm{Na}}$ kinetics (Liu et al., 2008), but could conceivably produce differences in activation voltage such as was observed in the present study. Perhaps more likely, $\mathrm{Na}^{+}$channel $\beta$-subunits are known to affect activation voltage (Johnson et al., 2004) and electrocytes of a related electric fish species express two $\mathrm{Na}^{+}$channel $\beta$-subunit splice variants (Liu et al., 2007).

Phosphorylation of $\mathrm{Na}^{+}$channels can alter a wide range of functional characteristics, including their activation/ inactivation kinetics (Catterall, 2012) and voltage dependence (Gasparini and Magee, 2002). Accordingly, differential phosphorylation of posterior and anterior membrane $\mathrm{Na}^{+}$channels in S. elegans electrocytes could lead to the differences in voltage dependence that we observed here. In addition, differential glycosylation of the anterior and posterior membrane $\mathrm{Na}^{+}$channel $\alpha$-subunits could be responsible for the observed differences in activation voltage because glycosylation of Nav1.4 is known to cause a hyperpolarizing shift in its activation voltage (Bennett, 2002). Given this range of possibilities, determination of the precise mechanism maintaining different $I_{\mathrm{Na}}$ activation voltages in S. elegans electrocytes will require additional experimentation to test these hypotheses.

Further experiments will also be necessary to fully explain the firing properties of S. elegans electrocytes. Our present computational model reproduces many important features of the electrocytes' APs and $\mu$ EODs. Most important, the present data and simulations demonstrate that observed differences in $\mathrm{Na}^{+}$channel activation voltage are adequate to explain the precise timing of two APs in S. elegans electrocytes. The present results, however, do not conclusively rule out the possibility that additional mechanisms contribute to the regulation of electrocyte AP initiation and timing. In addition, our best simulations at this point do not yet reproduce accurately all features of $\mu \mathrm{EOD}$ microstructure. This is likely because our model used $\mathrm{K}^{+}$currents with identical properties for both active compartments. Furthermore, it is possible that the $100 \mu \mathrm{M} \mathrm{Ba}^{2+}$ we used to block $I_{\mathrm{R}}$ during loose-patch recordings could have attenuated our recordings of $I_{\mathrm{A}}$ and $I_{\mathrm{K}}$, because $\mathrm{Ba}^{2+}$ concentrations in a similar range $(150 \mu \mathrm{M})$ are known to attenuate A-type $\mathrm{K}^{+}$currents in pyramidal neurons (Gasparini et al., 2007). Given the central role that $\mathrm{K}^{+}$currents play in shaping the AP waveform in excitable cells (Hille, 2001), a thorough characterization of electrocytes' voltage-gated $\mathrm{K}^{+}$currents will be necessary to fully account for the firing properties of S. elegans electrocytes and the resulting coding of critical social information in the EOD waveform.

\section{References}

Alle H, Geiger JR (2006) Combined analog and action potential coding in hippocampal mossy fibers. Science 311:1290-1293. CrossRef Medline

Alle H, Geiger JR (2008) Analog signalling in mammalian cortical axons. Curr Opin Neurobiol 18:314-320. CrossRef Medline

Almers W, Stanfield PR, Stühmer W (1983) Lateral distribution of sodium and potassium channels in frog skeletal muscle: measurements with a patch-clamp technique. J Physiol 336:261-284. Medline

Arnegard ME, Zwickl DJ, Lu Y, Zakon HH (2010) Old gene duplication facilitates origin and diversification of an innovative communication system-twice. Proc Natl Acad Sci U S A 107:22172-22177. CrossRef Medline

Bean BP (2007) The action potential in mammalian central neurons. Nat Rev Neurosci 8:451-465. CrossRef Medline

Bennett ES (2002) Isoform-specific effects of sialic acid on voltagedependent $\mathrm{Na}+$ channel gating: functional sialic acids are localized to the S5-S6 loop of domain I. J Physiol 538:675-690. CrossRef Medline

Bennett MV, Grundfest H (1959) Electrophysiology of electric organ in Gymnotus carapo. J Gen Physiol 42:1067-1104. CrossRef Medline

Bennett MVL (1961) Modes of operation of electric organs. Ann N Y Acad Sci 94:458-509.

Bennett MVL (1971) Electric organs. In: Fish physiology (Hoar WS, Randall DJ, eds), pp 347-491. New York: Academic.

Brand A, Behrend O, Marquardt T, McAlpine D, Grothe B (2002) Precise inhibition is essential for microsecond interaural time difference coding. Nature 417:543-547. CrossRef Medline

Catterall WA (2012) Voltage-gated sodium channels at 60: structure, function and pathophysiology. J Physiol 590:2577-2589. CrossRef Medline

Colbert CM, Pan E (2002) Ion channel properties underlying axonal action potential initiation in pyramidal neurons. Nat Neurosci 5:533-538. CrossRef Medline

de Polavieja GG, Harsch A, Kleppe I, Robinson HP, Juusola M (2005) Stimulus history reliably shapes action potential waveforms of cortical neurons. J Neurosci 25:5657-5665. CrossRef Medline

Eccles CU, Rogowski RS, Gu X, Alger BE, Blaustein MP (1994) Tityustoxin-K alpha, from scorpion venom, blocks voltage-gated, noninactivating potassium current in cultured central neurons. Neuropharmacology 33:1523-1528. CrossRef Medline

Friedman MA, Hopkins CD (1998) Neural substrates for species recognition in the time-coding electrosensory pathway of mormyrid electric fish. J Neurosci 18:1171-1185. Medline

Funabiki K, Ashida G, Konishi M (2011) Computation of interaural time difference in the owl's coincidence detector neurons. J Neurosci 31: 15245-15256. CrossRef Medline

Gasparini S, Magee JC (2002) Phosphorylation-dependent differences in the activation properties of distal and proximal dendritic $\mathrm{Na}+$ channels in rat CA1 hippocampal neurons. J Physiol 541:665-672. CrossRef Medline

Gasparini S, Losonczy A, Chen X, Johnston D, Magee JC (2007) Associative pairing enhances action potential back-propagation in radial oblique branches of CA1 pyramidal neurons. J Physiol 580:787-800. CrossRef Medline

Gavassa S, Silva AC, Stoddard PK (2011) Tight hormonal phenotypic integration ensures honesty of the electric signal of male and female Brachyhypopomus gauderio. Horm Behav 60:420-426. CrossRef Medline

Gavassa S, Goldina A, Silva AC, Stoddard PK (2013) Behavioral ecology, endocrinology and signal reliability of electric communication. J Exp Biol 216:2403-2411. CrossRef Medline

Hille B (2001) Ion channels of excitable membranes, Ed 3. Sunderland, MA: Sinauer.

Hopkins CD, Bass AH (1981) Temporal coding of species recognition signals in an electric fish. Science 212:85-87. CrossRef Medline

Hu W, Tian C, Li T, Yang M, Hou H, Shu Y (2009) Distinct contributions of Nav1.6 and Nav1.2 in action potential initiation and backpropagation. Nat Neurosci 12:996-1002. CrossRef Medline

Jercog PE, Svirskis G, Kotak VC, Sanes DH, Rinzel J (2010) Asymmetric excitatory synaptic dynamics underlie interaural time difference processing in the auditory system. PLoS Biol 8:e1000406. CrossRef Medline

Johnson D, Montpetit ML, Stocker PJ, Bennett ES (2004) The sialic acid component of the $\{$ beta $\} 1$ subunit modulates voltage-gated sodium channel function. J Biol Chem 279:44303-44310. CrossRef Medline

Johnston D, Christie BR, Frick A, Gray R, Hoffman DA, Schexnayder LK, Watanabe S, Yuan LL (2003) Active dendrites, potassium channels and synaptic plasticity. Philos Trans R Soc Lond B Biol Sci 358:667-674. CrossRef Medline

Kalman K, Pennington MW, Lanigan MD, Nguyen A, Rauer H, Mahnir V, Paschetto K, Kem WR, Grissmer S, Gutman GA, Christian EP, Cahalan MD, Norton RS, Chandy KG (1998) ShK-Dap22, a potent Kv1.3specific immunosuppressive polypeptide. J Biol Chem 273:32697-32707. CrossRef Medline

Kole MH, Ilschner SU, Kampa BM, Williams SR, Ruben PC, Stuart GJ (2008) 
Action potential generation requires a high sodium channel density in the axon initial segment. Nat Neurosci 11:178-186. CrossRef Medline

Lewis JE, Gilmour KM, Moorhead MJ, Perry SF, Markham MR (2014) Action potential energetics at the organismal level reveal a trade-off in efficiency at high firing rates. J Neurosci 34:197-201. CrossRef Medline

Liu H, Wu MM, Zakon HH (2007) Individual variation and hormonal modulation of a sodium channel beta subunit in the electric organ correlate with variation in a social signal. Dev Neurobiol 67:1289-1304. CrossRef Medline

Liu H, Wu MM, Zakon HH (2008) A novel $\mathrm{Na}+$ channel splice form contributes to the regulation of an androgen-dependent social signal. J Neurosci 28:9173-9182. CrossRef Medline

Markham MR (2013) Electrocyte physiology: 50 years later. J Exper Biol 216:2451-2458. CrossRef Medline

Markham MR, Stoddard PK (2005) Adrenocorticotropic hormone enhances the masculinity of an electric communication signal by modulating the waveform and timing of action potentials within individual cells. J Neurosci 25:8746-8754. CrossRef Medline

Markham MR, Kaczmarek LK, Zakon HH (2013) A sodium-activated potassium channel supports high-frequency firing and reduces energetic costs during rapid modulations of action potential amplitude. J Neurophysiol 109:1713-1723. CrossRef Medline

Matavel A, Cruz JS, Penaforte CL, Araújo DA, Kalapothakis E, Prado VF, Diniz CR, Cordeiro MN, Beirão PS (2002) Electrophysiological characterization and molecular identification of the Phoneutria nigriventer peptide toxin PnTx2-6. FEBS Lett 523:219-223. CrossRef Medline

Matsushita A, Kawasaki M (2005) Neuronal sensitivity to microsecond time disparities in the electrosensory system of Gymnarchus niloticus. J Neurosci 25:11424-11432. CrossRef Medline

Meeks JP, Mennerick S (2007) Action potential initiation and propagation in CA3 pyramidal axons. J Neurophysiol 97:3460-3472. CrossRef Medline
Moortgat KT, Keller CH, Bullock TH, Sejnowski TJ (1998) Submicrosecond pacemaker precision is behaviorally modulated: the gymnotiform electromotor pathway. Proc Natl Acad Sci U S A 95:4684-4689. CrossRef Medline

Palmer LM, Stuart GJ (2006) Site of action potential initiation in layer 5 pyramidal neurons. J Neurosci 26:1854-1863. CrossRef Medline

Roberts WM, Almers W (1984) An improved loose patch voltage clamp method using concentric pipettes. Pflugers Arch 402:190-196. CrossRef Medline

Salazar VL, Stoddard PK (2008) Sex differences in energetic costs explain sexual dimorphism in the circadian rhythm modulation of the electrocommunication signal of the gymnotiform fish Brachyhypopomus pinnicaudatus. J Exp Biol 211:1012-1020. CrossRef Medline

Salazar VL, Stoddard PK (2009) Social competition affects electric signal plasticity and steroid levels in the gymnotiform fish Brachyhypopomus gauderio. Horm Behav 56:399-409. CrossRef Medline

Salazar VL, Krahe R, Lewis JE (2013) The energetics of electric organ discharge generation in gymnotiform weakly electric fish. J Exp Biol 216: 2459-2468. CrossRef Medline

Stoddard PK (1999) Predation enhances complexity in the evolution of electric fish signals. Nature 400:254-256. CrossRef Medline

Stoddard PK, Markham MR (2008) Signal cloaking by electric fish. Bioscience 58:415-425. CrossRef Medline

Yan L, Herrington J, Goldberg E, Dulski PM, Bugianesi RM, Slaughter RS, Banerjee P, Brochu RM, Priest BT, Kaczorowski GJ, Rudy B, Garcia ML (2005) Stichodactyla helianthus peptide, a pharmacological tool for studying Kv3.2 channels. Mol Pharmacol 67:1513-1521. CrossRef Medline

Zakon HH, Lu Y, Zwickl DJ, Hillis DM (2006) Sodium channel genes and the evolution of diversity in communication signals of electric fishes: convergent molecular evolution. Proc Natl Acad Sci U S A 103:36753680. CrossRef Medline 